Supplement of Clim. Past Discuss., 11, 3799-3851, 2015

http://www.clim-past-discuss.net/11/3799/2015/

doi:10.5194/cpd-11-3799-2015-supplement

(C) Author(s) 2015. CC Attribution 3.0 License.

(c) (i)

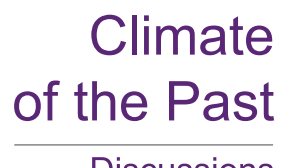

Discussions

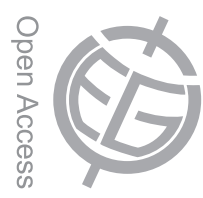

Supplement of

\title{
The "Dirty Weather" diaries of Reverend Richard Davis: insights about early Colonial-era meteorology and climate variability for Northern New Zealand, 1839-1851
}

\author{
A. M. Lorrey and P. R. Chappell \\ Correspondence to: A. M. Lorrey (a.lorrey@ niwa.co.nz)
}

The copyright of individual parts of the supplement might differ from the CC-BY 3.0 licence. 


\section{S1. Scanning and Transcription of the Davis Diary}

After permissions were granted to digitally image the Davis meteorological diary, an additional visit was undertaken to determine whether flatbed scanning or photography was the best method for capturing the source material. ACL graciously removed a small magnetic security strip that had been sown into the binder of the diary that enabled imaging to be undertaken with a portable flatbed scanner. Each diary page was scanned (see Figure 2 for an example) as a high-resolution tagged image format file (TIFF) and subsequently all the images were placed in archive on the NIWA server. In most cases more than one scan was needed to capture a single year's worth of data in the diary. Each TIFF file served as a master file that was locked to prevent alteration, and these master files were subsequently copied and divided into individual months. Scans for each month were parsed using cropping techniques in Adobe Photoshop. Subsequently, paper copies of the parsed monthly images were then printed in A3 format, which were then handled for data entry. Access to the original TIFF scans were also allowed for reference in case of clarity issues during data keying.

Diary entries were transcribed from the original handwritten version to MSExcel spreadsheet format to facilitate data analysis. As Davis' cursive handwritten script was sometimes difficult to decipher, significant care was taken when entering the data into the spreadsheet and optical character recognition was not possible. In cases where the handwriting was unclear, multiple team members were consulted and the data was only recorded once a consensus was reached. For numerical data (for example, temperature or pressure), monthly totals were calculated to check for data entry accuracy. When outliers were found during subsequent data analysis, the original handwritten diary and transcribed data was consulted to check for transcription errors. 